\title{
Effect of Surya Namaskar on High Sensitive C-Reactive Protein Levels in Overweight and Obese Middle Aged Adults
}

\author{
Richa Srivastav ${ }^{1}$, Divya Hyanki ${ }^{1{ }^{1,},}$, Pooja Chaurasia ${ }^{2}$, Ashutosh Bhardwaj ${ }^{3}$
}

Richa Srivastav ${ }^{1}$, Divya Hyanki ${ }^{1, *}$, Pooja Chaurasia ${ }^{2}$, Ashutosh Bhardwaj ${ }^{3}$

'Department of Physiology, S. N. Medical College, Agra, Uttar Pradesh, INDIA. ${ }^{2}$ Department of Physiology, Dr. RMLIMS, Lucknow, Uttar Pradesh, INDIA. ${ }^{3}$ Department of Physiology, Autonomous State Medical College Society, Firozabad, Uttar Pradesh, INDIA.

\section{*Correspondence}

\section{Dr. Divya Hyanki}

Junior resident, Department of Physiology, S. N. Medical College, Agra, Uttar Pradesh, INDIA. Postal address: Department of Physiology, Academic block, S. N. Medical College, Agra, Uttar Pradesh-282002, INDIA.

Phone: +91-8800746069

Email: hyankidivya@gmail.com

\section{History}

- Submission Date: 16-12-2019

- Review completed: 31-01-2020;

- Accepted Date: 25-02-2020

DOI : 10.5530/ijcep.2020.7.1.8

Article Available online

http://www.ijcep.org

\section{Copyright}

(c) 2020 Phcog.Net. This is an openaccess article distributed under the terms of the Creative Commons Attribution 4.0 International license.

\begin{abstract}
Background and Aim: With the increasing prevalence of overweight and obesity, the associated co-morbidities are also on the rise. High sensitive (hs-CRP) is an easily measured inflammatory biomarker and is considered an independent predictor of a possible future cardiovascular event and various other chronic diseases. The purpose of this study was to see the effect of Surya Namaskar on high sensitive CRP levels in overweight and obese middle aged adults. Methods: It was a single group prospective study. 50 overweight and obese individuals underwent a 12 weeks Surya Namaskar program. Their anthropometric measurements such as weight, body mass index, waist circumference, hip circumference and waist to hip ratio and hs-CRP levels were assessed at baseline and after 12 weeks. Results: Mean age of participants in the study was $48 \pm 6.36$ years. After 12 weeks there was significant decrease in the mean values of weight $(79.75 \pm 12.3 \mathrm{~kg}$ to $76.61 \pm 11.75 \mathrm{~kg})$, BMI $\left(29.34 \pm 3.29 \mathrm{~kg} / \mathrm{m}^{2}\right.$ to $\left.28.19 \pm 3.19 \mathrm{~kg} / \mathrm{m}^{2}\right)$, WC $(102.32 \pm 10.87 \mathrm{~cm}$ to $99.91 \pm 10.49 \mathrm{~cm})$, $\mathrm{HC}(106.41 \pm 9.97 \mathrm{~cm}$ to $104.05 \pm 9.64 \mathrm{~cm})$ and hs-CRP levels $(3.42 \pm 2.04 \mathrm{mg} / \mathrm{L}$ to $2.42 \pm 1.52 \mathrm{mg} / \mathrm{L})$. There was no significant change in WHR. Conclusion: Surya Namaskar results in a decrease in overall adiposity along with decrease in hs-CRP levels.
\end{abstract}

Key words: hs-CRP, Surya Namaskar, Obesity, Overweight, Middle aged.

\section{INTRODUCTION}

Globally, with growing urbanization and development, there has been an increase in the consumption of energy dense foods and decrease in the physical activity. Worldwide obesity has nearly tripled since 1975. Developing countries including India are seeing an upsurge in non-communicable disease risk factors such as obesity and overweight while combating the problems of infectious diseases and undernutrition. ${ }^{[1]}$ C-reactive protein belongs to the pentraxin family of calcium dependent ligand-binding plasma proteins and is synthesized by the liver. Traditionally it is a sensitive marker of systemic inflammation. Studies have linked CRP with obesity. ${ }^{[2]}$ Its levels measured by high-sensitive CRP assay (hs-CRP) are of importance for cardiovascular disease risk stratification. Levels of less than 1 , between 1 to 3 , and greater than $3 \mathrm{mg} / \mathrm{L}$ are associated with lower, moderate, and higher cardiovascular risks, respectively. ${ }^{[3]}$

Surya Namaskar or sun salutation is a combination of yogic postures that is performed in synchrony with the breath. It is considered an integral part of modern yoga training but is deficient in the scientific literature on its physiological effects. Studies where the energy cost and cardiorespiratory changes during the practice were studied concluded that Surya Namaskar is an ideal form of aerobic exercise having static, stretching and dynamic muscular movements involving all major joints. ${ }^{[4,5]}$

\section{MATERIALS AND METHODS}

The present study was conducted in the Department of Physiology, S.N. Medical College, Agra. It was a single group prospective study aimed to analyse the effect of Surya Namaskar on hs-CRP levels in overweight and obese middle aged adults. Approval of Institutional research and ethics committees was taken.

50 middle aged individuals who had newly joined various yoga centres in Agra were selected by quota sampling technique. Written informed consent was obtained from all the participants.

\section{Inclusion Criteria}

- $\quad$ All the individuals with $\mathrm{BMI} \geq 25$, between 40-60 years, who were willing to participate in the study voluntarily after being informed in details about the study were included in the study.

\section{Exclusion Criteria}

- Individuals who were not willing to participate.

- Individuals with hs-CRP levels more than $10 \mathrm{mg} / \mathrm{L}$.

Cite this article: Srivastav R, Hyanki D, Chaurasia P, Bhardwaj A. Effect of Surya Namaskar on High Sensitive C-Reactive Protein Levels in Overweight and Obese Middle Aged Adults. Int J Clin Exp Physiol. 2020;7(1):33-5 
- Individuals having any acute infection, secondary obesity, diabetes or hypertension, hereditary or systemic inflammatory diseases or in any significant physical training programs.

- Pregnant or lactating females.

- Individuals with spine deformity.

\section{Methodology}

After all the participants were briefed regarding the purpose and methodology of study, detailed history was taken and weight, body mass index, waist circumference, hip circumference, waist to hip ratio and hs-CRP levels were assessed. They underwent 12 weeks of surya namaskar program. Participants started with 5 rounds a day and by the end of the week it was 10 rounds a day. From second week onwards it was 12 rounds of surya namaskar in the morning, 6 days a week it was supervised and on Sundays participants were urged to do it in their homes. Each set of surya namaskar was performed at an intermediate pace of one and a half minutes. At the end of 12 weeks, all the anthropometric parameters and hs-CRP levels were reassessed.

\section{Anthropometric Profile}

Participants were asked to wear light clothing without shoes. Weight was recorded in kilograms by asking them to stand erect on the centre of the weighing machine. Height was measured with the participants standing against an upright surface with their heels, buttocks and back touching on a level smooth surface. BMI was calculated as body weight in kilogram divided by square of height in meters. The cut off was 25 as per the WHO standards.

Waist and hip circumference were measured in centimetres by applying flexible measuring tape tautly on the skin surface at the level of 1 inch above umbilicus and at the level of widest portion of the buttocks, respectively, with participants standing erect with arms by the side and feet positioned close together. The waist-to-hip ratio was calculated as waist circumference divided by hip circumference.

\section{Biochemical Analysis}

After venepuncture, $5 \mathrm{ml}$ of venous blood was collected in a red vacutainer. The sample was centrifuged within an hour to obtain serum for estimation of hs-CRP levels. Quantitative estimation was done by immunoturbidimetric assay using Roche Cobas 6000 analyser.

\section{Statistical Analysis of Data}

All the data was entered into MS excel spreadsheets and analysed with the help of SPSS version 20.0. Descriptive statistics was explained by frequency and percentage. Quantitative data was presented as mean and standard deviation. Paired $t$ test was used to compare the pre and post values. Statistical significance was considered with $\mathrm{p}$ value $<0.05$.

\section{RESULTS}

Table 1 and 2 shows the distribution of participants. A total of 50 individuals were interviewed and examined. Gender wise there was equal distribution of participants with the mean age of the participants being $48.34 \pm 6.36$ years. $56 \%$ participants were overweight and $44 \%$ were obese.

Table 3 stratifies the participants according to the associated cardiovascular risks. We saw a shift after 12 weeks with $12 \%$ increase in participants at low risk, $6 \%$ increase in those at moderate risk and 18\% decrease in participants at high risk of cardiovascular accidents.

The comparison of parameters at baseline and after 12 weeks of Surya Namaskar is shown in Table 4 . The mean values of weight, body mass index, waist circumference and hip circumference showed a significant decrease after 12 weeks in comparison to values at baseline. However,
Table 1: Distribution of participants based on gender.

\begin{tabular}{ccc}
\hline Gender & No. of participants & Total (\%) \\
\hline Male & 25 & 50.0 \\
Female & 25 & 50.0 \\
Total & 50 & 100
\end{tabular}

Table 2: Distribution of participants based on gender and BMI.

\begin{tabular}{|cccc|}
\hline BMI $\left(\mathrm{kg} / \mathrm{m}^{2}\right)$ & \multicolumn{2}{c}{ Gender } & Total (\%) \\
& Male (\%) & Female (\%) & \\
$25-29.9$ & $15(60.0)$ & $13(52.0)$ & $28(56.0)$ \\
$\geq 30$ & $10(40.0)$ & $12(84.0)$ & $22(44.0)$ \\
Total & $25(100.0)$ & $25(100.0)$ & $50(100.0)$ \\
\hline
\end{tabular}

Table 3: Distribution of participants Hs-CRP levels as per associated CV risk at the baseline and after 12 weeks.

\begin{tabular}{|ccc|}
\hline Hs-CRP & Baseline & After 12 weeks \\
$<1 \mathrm{mg} / \mathrm{L}$ & 0 & $6(12 \%)$ \\
$1-3 \mathrm{mg} / \mathrm{L}$ & $26(52 \%)$ & $29(58 \%)$ \\
$>3 \mathrm{mg} / \mathrm{L}$ & $24(48 \%)$ & $13(30 \%)$ \\
Total & 50 & 50 \\
\hline
\end{tabular}

Table 4: Comparison of parameters at baseline and after 12 weeks of Surya Namaskar.

\begin{tabular}{ccccc} 
& $\begin{array}{c}\text { Time of data } \\
\text { collection } \\
\text { Parameter }\end{array}$ & $\begin{array}{c}\text { Paired } \\
\text { Difference }\end{array}$ & \multicolumn{2}{c}{ P value } \\
& Baseline & After & & \\
Weight $(\mathrm{kg})$ & $79.75 \pm 12.3$ & $76.61 \pm 11.75$ & $3.13 \pm 1.41$ & $<0.001$ \\
$\begin{array}{c}\text { Body mass index } \\
\left(\mathrm{kg} / \mathrm{m}^{2}\right)\end{array}$ & $29.34 \pm 3.29$ & $28.19 \pm 3.19$ & $1.15 \pm 0.5$ & $<0.001$ \\
$\begin{array}{c}\text { Waist } \\
\text { circumference }(\mathrm{cm})\end{array}$ & $102.32 \pm 10.87$ & $99.91 \pm 10.49$ & $2.41 \pm 1.35$ & $<0.001$ \\
$\begin{array}{c}\text { Hip circumference } \\
(\mathrm{cm})\end{array}$ & $106.41 \pm 9.97$ & $104.05 \pm 9.64$ & $2.36 \pm 1.29$ & $<0.001$ \\
$\begin{array}{c}\text { Waist-Hip ratio } \\
\text { hs-CRP (mg/l) }\end{array}$ & $0.958 \pm 0.075$ & $0.956 \pm 0.071$ & $0.002 \pm 0.01$ & 0.280 \\
& $3.42 \pm 2.04$ & $2.42 \pm 1.52$ & $1.00 \pm 0.90$ & $<0.001$
\end{tabular}

waist-hip ratio showed no significant change after 12 weeks. The mean value of hs-CRP among all the participants at the start of the study was $3.42 \pm 2.04 \mathrm{mg} / \mathrm{L}$ and this was reduced to $2.42 \pm 1.52 \mathrm{mg} / \mathrm{L}$.

\section{DISCUSSION}

While performing surya namaskar there is stretching and strengthening of muscles throughout the body along with regulation of breathing. Mody BS found that every 15 minutes spent while performing surya namaskar expended $100 \mathrm{kcal}$. He suggested that performing surya namaskar at a pace of $3 \mathrm{~min} /$ round met with the guidelines of American College of sports medicine for energy expenditure in weight management. ${ }^{[6]}$ In our study the participants performed at similar pace and we observed a significant reduction in the weight, BMI, WC and $\mathrm{HC}$ of the participants. Studies by Shete SU et al in 2012 and 2017, Balaji P et al in 2017 observed significant decrease in hs-CRP levels in yoga group. ${ }^{[7-9]}$ Shukla $\mathrm{R}$ et al in 2016 found that after yogic interventions there was highly significant change in BMI, CRP, resistin and RBS. ${ }^{[10]}$ Irandoust $\mathrm{K}$ et al in 2019 
concluded that CRP in yoga and strength training groups was lower than in control group. ${ }^{[1]}$ Studies by Parma DL et al, Wolff M et al in 2015 and Azami M et al in 2019 found insignificant changes in inflammatory serum markers after yogic intervention. ${ }^{[12-14]}$ Studies have suggested that adipose tissue may be directly involved in the production and regulation of cytokines such as IL- 6 and TNF- $\alpha$ that induce hs-CRP production. ${ }^{[15]}$ Thus reduction in adiposity may have been responsible for the fall in hs-CRP levels by Surya Namaskar.

Currently, retrograde inflammation has been identified as a pathophysiologic mechanism of diabetes, hypertension and many other lifestyle related disorders. hs-CRP is a marker of retrograde inflammation and hs-CRP has been established as a standard laboratory index of cardiovascular risks. Therefore, practice of Surya Namaskar decreasing the level of hs-CRP in middle aged adults opens up the scope for further research in reduction of cardiovascular risks through such yogic practice.

\section{Limitations of the Study}

- It is a single group study which lacked individuals with normal BMI.

- Selection and exclusion of the individuals was done on the basis of history and examination.

- The comparison of data has not been made between overweight and obesity groups in the present study

\section{CONCLUSION}

After 12 weeks of Surya Namaskar program we found significant decrease in the mean values of weight, body mass index, waist circumference and hip circumference. We also observed a significant reduction in the hs-CRP levels. Thus, we would to conclude that regular practice of Surya Namaskar seems to have a positive impact on the obesity indices and hs-CRP levels.

\section{ACKNOWLEDGEMENT}

I'm extremely grateful to Dr. Arun Kumar Chaturvedi for his tremendous help.

\section{CONFLICT OF INTEREST}

Authors declare that they have no conflict of interest.

\section{ABBREVIATIONS}

hs-CRP: High-sensitive CRP assay.

\section{REFERENCES}

1. WHO factsheet 2018 [https://www.who.int/en/news-room/fact-sheets/detail/ obesity-and-overweight]

2. Brooks GC, Blaha MJ, Blumenthal RS. Relation of C-reactive protein to abdominal adiposity. Am J Cardiol. 2010;106(1):56-61.

3. Bassuk SS, Rifai N, Ridker PM. High sensitivity C-Reactive Protein: clinical importance. Curr Prob Cardiol. 2004;29(8):439-93.

4. Sinha B, Ray US, Pathak A, Selvamurthy W. Energy cost and cardiorespiratory changes during the practice of surya namaskar. Ind J Physiol Pharmacol. 2004;48(2):184-90.

5. Bhutkar MP, Bhutkar VM, Taware BG, Doijad V, Doddamani BR. Effect of suryanamaskar practice on cardio-respiratory fitness parameters: A Pilot Study. Al Ameen J Med Sci. 2008;1(2):126-9.

6. Mody BS. Acute effects of Surya Namaskar on the cardiovascular and metabolic system. J Bodyw Mov Ther. 2011;15(3):343-7.

7. Shete Sanjay U, Kulkarni DD, Thakur GS. Effect of yoga practices on hs-CRP in Indian Railway engine drivers of metropolis. Rec Res Sci Tech. 2012;4:30-3.

8. Shete SU, Verma A, Kulkarni DD, Bhogal RS. Effect of yoga training on inflammatory cytokines and C-reactive protein in employees of small-scale industries. J Educ Health Promot. 2017;6:76.

9. Balaji PA, Varne SR. High sensitive CRP levels, Plasma renin activity and blood pressure among Hypertensive patients practicing Yoga exercises. Ind J Clin Anat Physiol. 2017;4(4):431-4.

10. Shukla R, Gehlot S. Response of paschimottanasana and kapalabhati on CRP, resistin and RBS in obese individuals. Int J Res Ayurveda Pharm. 2016;7:160-4.

11. Irandoust K, Taheri M. Effect of Peripheral Heart Action Training and Yoga Exercise Training on Respiratory Functions and C-Reactive Protein of Postmenopausal Women. Women's Health Bulletin. 2019;6(2):e88027.

12. Parma DL, Hughes D, Ghosh S, Li R, Whitaker R, Ogden S, et al. Effect of 6 month of yoga on inflammatory serum markers prognostic of recurrence risk in breast cancer survivors. Spring Plus. 2015;4(1):143.

13. Wolff M, Memon AA, Chalmers JP, Sundquist K, Midlöv P. Yoga's effect on inflammatory biomarkers and metabolic risk factors in a high risk population -a controlled trial in primary care. BMC Cardiovascular Disorders. 2015;15.

14. Azami M, Hafezi AMR, Yekta KMH, Qavam S. Effect of Yoga on Lipid Profile and C-reactive Protein in Women. Int J Prev Med. 2019:10:81.

15. Leal O, Mafra D. Adipokines in obesity. Int J Clin Chem. 2013;419:87-94.

Cite this article: Srivastav R, Hyanki D, Chaurasia P, Bhardwaj A. Effect of Surya Namaskar on High Sensitive C-Reactive Protein Levels in Overweight and Obese Middle Aged Adults. Int J Clin Exp Physiol. 2020;7(1):33-5. 